Resection margins and local recurrences of impalpable breast

cancer : Comparison between radioguided occult lesion localization (ROLL) and radioactive seed localization (RSL)

\author{
Niinikoski, Laura
}

2019-10

Niinikoski , L, Hukkinen, K, Leidenius, M H K, Vaara, P, Voynov, A, Heikkila, P , Mattson , J \& Meretoja , T J 2019 , ' Resection margins and local recurrences of impalpable breast cancer : Comparison between radioguided occult lesion localization (ROLL) and radioactive seed localization (RSL) ' , Breast , vol. 47 , pp. 93-101 . https://doi.org/10.1016/j.breast.2019.07.004

http://hdl.handle.net/10138/319380

https://doi.org/10.1016/j.breast.2019.07.004

unspecified

publishedVersion

Downloaded from Helda, University of Helsinki institutional repository.

This is an electronic reprint of the original article.

This reprint may differ from the original in pagination and typographic detail.

Please cite the original version. 
Original article

\title{
Resection margins and local recurrences of impalpable breast cancer: Comparison between radioguided occult lesion localization (ROLL) and radioactive seed localization (RSL)
}

\author{
Laura Niinikoski ${ }^{\text {a, }}$, Katja Hukkinen ${ }^{\text {b }}$, Marjut H.K. Leidenius a , Päivi Vaara a, \\ Aleksandar Voynov ${ }^{a}$, Päivi Heikkilä ${ }^{c}$, Johanna Mattson ${ }^{d}$, Tuomo J. Meretoja a \\ ${ }^{a}$ Breast Surgery Unit, Comprehensive Cancer Center, University of Helsinki, Helsinki University Hospital Finland, P.O. Box 263, 00029, HUS, Finland \\ ${ }^{\mathrm{b}}$ HUS Medical Imaging Center, Radiology, University of Helsinki and Helsinki University Hospital, P.O. Box 263, 00029, HUS, Finland \\ ${ }^{c}$ Department of Pathology, University of Helsinki, Helsinki University Hospital Finland, P.O. Box 400, 00029, HUS, Finland \\ ${ }^{\mathrm{d}}$ Comprehensive Cancer Center, University of Helsinki, Helsinki University Hospital Finland, PO Box 180, 00029, HUS, Finland
}

\section{A R T I C L E I N F O}

\section{Article history:}

Received 23 May 2019

Received in revised form

28 June 2019

Accepted 22 July 2019

Available online 23 July 2019

\section{Keywords:}

Breast cancer

Breast conserving surgery

Radioguided occult lesion localization

Radioactive seed localization

Surgical margins

Local recurrence

\begin{abstract}
A B S T R A C T
Objectives: The aim of this retrospective study is to compare surgical margins, reoperation rates and local recurrences after breast conserving surgery (BCS) using radioguided occult lesion localization (ROLL) or radioactive seed localization $(\mathrm{RSL})$.

Materials and methods: We reviewed 744 consecutive patients with impalpable primary invasive breast cancer who underwent BCS at Helsinki University Hospital between 2010 and 2012. ROLL was used in our unit until October 31st, 2011; from November 1st we changed localization method to RSL.

Results: 318 patients underwent ROLL and 426 RSL. Patients in the RSL group had more often multifocal $(\mathrm{p}=0.013)$ tumours. No statistically significant differences were found regarding tumour size, specimen weight, histology or grade of tumours or lymph node status. $42(5.6 \%)$ patients were reoperated because of insufficient margins, 13 (4.1\%) in the ROLL group and $29(6.8 \%)$ in the RSL group. The reoperation rate was not different between the groups either in the univariable analysis $(\mathrm{p}=0.112)$ or in the multivariable binary logistic regression analysis $(p=0.204)$. Risk factors for reoperations were multifocality of the tumour $(p<0.001)$, extensive intraductal component $(p<0.001)$, larger tumour size $(p=0.011)$, and smaller specimen weight $(\mathrm{p}=0.014)$. The median follow-up time in the ROLL group was $81(8-94)$ months and 64 (3-73) months in the RSL group. The five-year local recurrence-free survival (LRFS) estimates for ROLL and RSL groups were $98.0 \%$ and $99.4 \%$, respectively (log-rank test, $p=0.323$ ). Conclusion: Reoperation rates and LRFS were comparable for ROLL and RSL in patients with impalpable breast cancer treated with BCS.
\end{abstract}

๑) 2019 Elsevier Ltd. All rights reserved.

\section{Introduction}

The number of impalpable malignant breast tumours has increased due to improved imaging and screening programmes. Breast conserving surgery (BCS) in patients with impalpable tumours requires precise preoperative lesion localization to ensure adequate surgical margins. Furthermore, the aim in BCS is to achieve good aesthetic result by minimizing the amount of resected healthy breast tissue [1].

\footnotetext{
* Corresponding author. Breast Surgery Unit, Comprehensive Cancer Center Helsinki University Hospital, P.O. Box 263, 00029, HUS, Finland.

E-mail address: laura.niinikoski@hus.fi (L. Niinikoski).
}

Wire-guided localization (WGL) has been the gold standard for surgical excision of impalpable breast lesions. There are, however, some downsides with WGL. It has rates of incomplete surgical excision ranging from $12 \%$ to $60 \%$ [2-5]. Furthermore, WGL is unpleasant for patient and scheduling of wire insertion and surgery can be challenging. Therefore, other localization methods have been introduced.

Radioguided occult lesion localization (ROLL) is a technique using albumin particles labelled with radioactive technetium (Tc$99 \mathrm{~m}$ ), which is injected before surgery intra- or peritumorally under ultrasound (US) or stereotactic guidance. Intraoperatively a gamma probe is used to detect the radioactivity; the same probe is used for sentinel lymph node biopsy (SLNB). 


$\begin{array}{ll}\text { Abbreviations } \\ \text { BCS } & \text { Breast conserving surgery } \\ \text { WGL } & \text { Wire-guided localization } \\ \text { ROLL } & \text { Radioguided occult lesion localization } \\ \text { US } & \text { Ultrasound } \\ \text { SLNB } & \text { Sentinel lymph node biopsy } \\ \text { RSL } & \text { Radioactive seed localization } \\ \text { LR } & \text { Local recurrence } \\ \text { DCIS } & \text { Ductal carcinoma in situ } \\ \text { RT } & \text { Radiotherapy } \\ \text { CNB } & \text { Core needle biopsy } \\ \text { FNAC } & \text { Fine needle aspiration cytology } \\ \text { MRI } & \text { Magnetic resonance imaging } \\ \text { MDT } & \text { Multidisciplinary team } \\ \text { CT } & \text { Computed tomography scan } \\ \text { LRFS } & \text { local recurrence-free survival } \\ \text { EIC } & \text { Extensive intraductal component }\end{array}$

Radioactive seed localization (RSL) technique is using iodine125 -containing titanium seed, also inserted under US or stereotactic guidance into the center of the tumour. The tumour and the seed can be detected intraoperatively accurately using gamma probe likewise. RSL can be performed well ahead of surgery with flexible scheduling, since the half-life of iodine- 125 is significantly longer compared to technetium-99 m (60 days vs. $6 \mathrm{~h}$ ) [5].

There are several studies comparing ROLL or RSL to WGL [6-8] but only few comparing ROLL and RSL [9-11]. The aim of this retrospective study is to compare surgical margins, reoperation rates and local recurrences (LR) after BCS using ROLL and RSL.

\section{Material and methods}

1876 consecutive patients with primary invasive breast cancer or ductal carcinoma in situ (DCIS) who underwent BCS at Breast Surgery Unit of Helsinki University Hospital between the January 1st, 2010 and December 31st, 2012 were reviewed for this retrospective cohort study. None of the patients received neoadjuvant treatment.

We excluded patients who underwent a lumpectomy with neither adjuvant treatment nor axillary surgery due to comorbidities, patients who had been diagnosed by surgical biopsy and those whose breast cancer was found unexpectedly in reduction mammoplasty specimen. Furthermore, we excluded patients with palpable tumours, those who underwent other localization procedure than ROLL or RSL and patients with pure DCIS. In the remaining 744 patients, tumours were localized using either ROLL or RSL (Fig. 1).

ROLL was used in our unit until October 31st, 2011, since then we used RSL. During the ROLL era, WGL was used for large area of microcalcifications and for multifocal tumours. In addition, WGL was used in DCIS, when there was no need for SLNB. During the RSL era WGL was used only occasionally. In total, there were 93 patients with pure DCIS; 13 of them underwent ROLL and 30 RSL. Due to the small number of eligible DCIS cases, especially in the ROLL group, the analysis for pure DCIS cases was performed separately.

Patient, tumour, treatment and follow-up data was collected from electronic patient records. Synchronous bilateral cancer was regarded as two separate cases when assessing primary surgical outcome. Bilateral disease was excluded from the survival analysis.

\subsection{Imaging}

All patients underwent preoperative mammography and breast and axillary US. Core needle biopsy (CNB) was taken from breast lesion(s) and fine needle aspiration cytology (FNAC) from suspicious axillary lymph nodes. Patients who had an invasive lobular carcinoma diagnosed on CNB underwent magnetic resonance imaging (MRI).

\subsection{Tumour localization technique}

The image-guided localization was performed or supervised by experienced breast radiologists. Both ROLL and RSL were performed under US or stereotactic guidance, dependent upon the visibility of the tumour. In ROLL, a single peritumoural 100-120 MBq Tc-99 m nanocolloid injection was used and utilized for the SLNB. A lymphoscintigraphy with dual-head gamma camera was obtained $1.5-3 \mathrm{~h}$ after injection to exclude leakage and to identify the sentinel nodes. The RSL was performed within four weeks prior to surgery. Iodine-125-radiolabeled seeds (Oncura, RAPID Strand, Arlington Heights,Ill, USA) were used. The 4.5 by $0.8 \mathrm{~mm}$ titaniumencapsulated seed was placed inside an 18-gauge needle and aimed at the center of the tumour. A two-view mammography (craniocaudal and lateromedial) was performed to confirm correct placement of the seed.

During surgery, the seed or the nanocolloid was localized using a handheld gamma probe and the tumour area was excised. A specimen radiography was routinely performed to assess the radiological margins and in case of RSL, to confirm the presence of the seed. Specimen US was performed whenever needed, at the discretion of the breast radiologist.

\subsection{Surgical technique}

All breast and axillary operations were performed or supervised by experienced breast surgeons. Surgeon decided on the operation technique individually depending on the location and size of the tumour, as well as on the size and the glandular density of breast, in agreement with the patient. In this study, conventional BCS stands for resection of the tumour with adequate mobilization and closure of breast tissue. Oncoplastic BCS instead refers to other level 1 and level 2 oncoplastic procedures [12,13].

Patients with axillary lymph node metastasis in US guided FNAC underwent axillary lymph node dissection. SLNB was performed in remaining patients.

Reoperation due to inadequate margins was either a re-excision or a mastectomy and was dependent on breast size, glandular density and aesthetic result after the first operation, with patient's preference taken into account. The guidelines for adequate surgical margins changed at the beginning of the study period in 2010, the new recommendations were adopted in our unit gradually. Previously $5 \mathrm{~mm}$ microscopical histological margins were required for invasive cancer and $10 \mathrm{~mm}$ for DCIS. Consensus symposium in 2010 recommended that no ink on tumour is adequate for invasive cancer and $2 \mathrm{~mm}$ for DCIS [14]. At our unit, the recommended DCIS margins were applied for margins of the intraductal component in patients with invasive cancer.

\subsection{Histopathological examination}

Histopathological analyses from surgical specimens were performed by experienced breast pathologists. The breast and lymph node specimens were handled and examined as described in our earlier study [15]. 


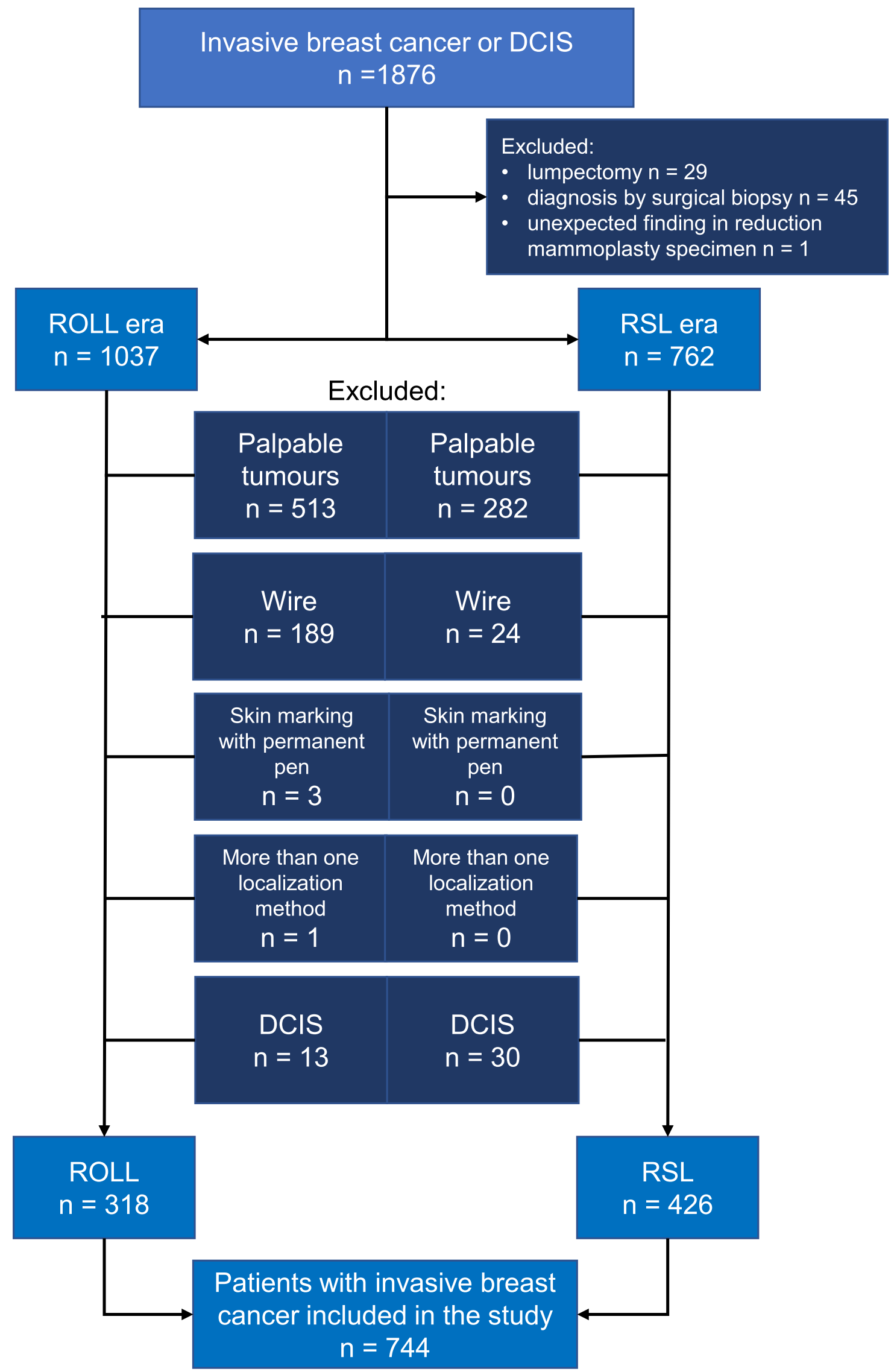

Fig. 1. Patient inclusion flowchart. 


\subsection{Adjuvant treatment}

All cases were discussed at a multidisciplinary team (MDT) meeting after surgery in order to recommend adjuvant treatment. All patients received postoperative RT except those who underwent mastectomy as a second operation and those who were not fit for RT or refused RT. Patients who had distant metastases identified on postoperative whole body computed tomography scan (CT) did not receive RT either. Adjuvant chemotherapy and endocrine treatment were recommended according to the Finnish national evidencebased guidelines [16]. The RT and adjuvant systemic treatment protocols used at our institution are described in our earlier study [17].

\subsection{Follow-up}

The first clinical checkup took place within three weeks after the operation. After adjuvant treatment, the patients were followed-up at the Department of Oncology of Helsinki University Hospital for 5-10 years, according to the risk of recurrence. The follow-up consisted of visits at least at one, three and five years after the operation.

Mammography was performed annually, combined with US in women $\leq 45$ years of age, in women with high density of breast in mammography or if needed as further diagnostic investigation. Annual breast MRI was performed in women with hereditary breast cancer. Additionally, MRI, whole body CT or bone isotope scan were performed whenever indicated for instance due to symptoms which might indicate local or distant recurrence.

In addition, all patients had an access to an outpatient clinic whenever there were concerns regarding symptoms related to side effects of treatments or potential recurrence.

After the first 5-10 years, the follow-up continued at primary health care, according to regional guidelines.

\subsection{Statistical analyses}

Statistical analyses were performed using IBM ${ }^{\text {тм }}$ SPSS tics version 22 software (SPSS Inc., Chicago, IL). Frequency tables were analyzed with chi-squared test and continuous distributions with Mann-Whitney $U$ test.

Independent variables with p-values $<0.15$ in the univariable analyses were entered into a backward stepwise binary logistic regression analysis to evaluate their association with need for reoperation due to insufficient margins in a multivariable model. At each step of the analysis, the variable with the highest p-value was eliminated until the remaining variables had p-values $<0.05$.

For breast cancer events, we excluded patients with bilateral disease $(n=51)$, earlier breast cancer $(n=28)$, other malignancy (apart from DCIS or basal cell carcinoma) within five years $(\mathrm{n}=44)$, distant metastasis diagnosed within 12 months after primary operation $(\mathrm{n}=2)$ and those who underwent a completion mastectomy $(n=26)$. In addition, we excluded patients who were followed-up for less than three years due to migration to other hospital district $(\mathrm{n}=14)$.

The remaining 579 patients went through a Kaplan-Meier survival analysis for local recurrence-free survival (LRFS), and the ROLL and RSL groups were compared with the log-rank test. Other breast cancer events were assessed with Fisher's exact test simply comparing event counts.

\section{Results}

The patient and tumour characteristics are summarized in Table 1 as well as adjuvant therapy. ROLL was performed in 318
(42.7\%) patients and RSL in 426 (57.3\%). The patients in the ROLL group were slightly younger $(\mathrm{p}=0.033)$. The median tumour size was $10 \mathrm{~mm}(1-40 \mathrm{~mm})$ in the ROLL group and $11 \mathrm{~mm}(1-55 \mathrm{~mm})$ in the RSL group $(\mathrm{p}=0.219)$. There were no differences between the groups regarding $\mathrm{pT} 1 \mathrm{a}-\mathrm{c}$ subgroups $(\mathrm{p}=0.815)$.

Histological subtypes were distributed similarly in the groups $(p=0.469)$, but the tumours in the ROLL group had higher proliferation index Ki-67 ( $p=0.031)$. Patients in the RSL group had more often multifocal ( $\mathrm{p}=0.013)$ tumours; $60(14.1 \%)$ tumours in the RSL group were multifocal compared to $26(8.2 \%)$ in the ROLL group. No significant differences between the ROLL and RSL groups were found regarding specimen weight, grade of tumours or lymph node status.

$79(24.8 \%)$ patients in ROLL group and 120 patients $(28.2 \%)$ in the RSL group underwent oncoplastic BCS $(p=0.311)$. Various oncoplastic techniques were used and the amount of resected tissue varied substantially depending on the surgical technique (range 8-1893 g) [13].

More patients in the RSL group received adjuvant endocrine treatment.

\subsection{Reoperations}

Surgical margins were wider in the ROLL group, though the median of the smallest lateral surgical margin was $10 \mathrm{~mm}$ in the both groups ( $\mathrm{p}=0.011$ ) (Table 1$)$. However, there was no statistically significant difference in insufficient surgical margins or reoperation rate between the groups $(p=0.112)$ in the univariable analysis. 42 (5.6\%) patients were reoperated because of insufficient margins, 13 (4.1\%) in the ROLL group and 29 (6.8\%) in the RSL group (Table 2).

Risk factors for reoperations in the univariable analysis were multifocality of the tumour $(\mathrm{p}<0.001)$ and extensive intraductal component (EIC) $(\mathrm{p}<0.001)$. Altogether, 86 patients had multifocal tumours, 18 (20.9\%) of them underwent a reoperation, compared to 24 (3.6\%) out of 658 patients with unifocal tumours. Twelve $(20.0 \%)$ patients out of 60 with EIC underwent a reoperation compared to 30 (4.4\%) out of 684 without EIC.

In the multivariable binary logistic regression analysis multifocality of the tumour $(\mathrm{p}<0.001)$ and EIC $(\mathrm{p}<0.001)$ remained risk factors for reoperation (Table 3 ). Furthermore, larger tumour size $(\mathrm{p}=0.011)$ and smaller specimen weight $(\mathrm{p}=0.014)$ were statistically significant factors predicting a reoperation. There was no statistically significant difference in the reoperation rate between the ROLL and RSL $(p=0.204)$ in the multivariable binary logistic regression analysis either.

The second operation was a re-excision for 11 patients (26.2\%) and mastectomy for 31 (73.8\%). Five patients underwent a reexcision in the ROLL group and six in the RSL group, a completion mastectomy was performed in eight patients in the ROLL group and in 23 the RSL group $(\mathrm{p}=0.226)$.

\subsection{Breast cancer recurrence}

Altogether 579 patients remained for survival analysis of LRFS, 258 in the ROLL group and 321 in the RSL group (Table 4). The median follow-up time in the ROLL group was 81 (8-94) months and 64 (3-73) months in the RSL group. Seven (2.7\%) patients in the ROLL group developed an ipsilateral LR and three $(0.9 \%)$ in the RSL group. The five-year LRFS estimates for ROLL and RSL groups were $98.0 \%$ and $99.4 \%$, respectively (log-rank test, $\mathrm{p}=0.323$, Fig. 2 ).

All breast cancer events are summarized in Table 4. Distant metastases were detected in three (1.2\%) patients in the ROLL group and likewise in three $(0.9 \%)$ in the RSL group (Fisher's test, $\mathrm{p}=1.000$ ). 
Table 1

Patient and tumour characteristics for ROLL and RSL.

\begin{tabular}{|c|c|c|c|c|c|c|}
\hline & & \multicolumn{2}{|c|}{ ROLL N = $318(42.7 \%)$} & \multicolumn{2}{|c|}{ RSL N = $426(57.3 \%)$} & \multirow[t]{2}{*}{ p-value } \\
\hline & & $\mathrm{N}$ & $\%$ & $\mathrm{~N}$ & $\%$ & \\
\hline \multirow[t]{2}{*}{ Surgery } & Conventional BCS & 239 & $75.2 \%$ & 306 & $71.8 \%$ & \multirow[t]{2}{*}{0.311} \\
\hline & Oncoplastic BCS & 79 & $24.8 \%$ & 120 & $28.2 \%$ & \\
\hline \multirow[t]{2}{*}{ Reoperation due to insufficient margins } & No & 305 & $95.9 \%$ & 397 & $93.2 \%$ & \multirow[t]{2}{*}{0.112} \\
\hline & Yes & 13 & $4.1 \%$ & 29 & $6.8 \%$ & \\
\hline \multirow[t]{2}{*}{ Reoperation } & Re-excision & 5 & $38.5 \%$ & 6 & $20.7 \%$ & \multirow[t]{2}{*}{0.226} \\
\hline & Mastectomy & 8 & $61.5 \%$ & 23 & $79.3 \%$ & \\
\hline \multirow[t]{3}{*}{ Histology } & Invasive ductal carcinoma & 230 & $72.3 \%$ & 291 & $68.3 \%$ & \multirow[t]{3}{*}{0.469} \\
\hline & Invasive lobular carcinoma & 39 & $12.3 \%$ & 63 & $14.8 \%$ & \\
\hline & Other invasive & 49 & $15.4 \%$ & 72 & $16.9 \%$ & \\
\hline \multirow[t]{3}{*}{ Pathological T stage } & pT1 & 304 & $95.6 \%$ & 400 & $93.9 \%$ & \multirow[t]{3}{*}{0.461} \\
\hline & pT2 & 14 & $4.4 \%$ & 25 & $5.9 \%$ & \\
\hline & pT3 & 0 & $0.0 \%$ & 1 & $.2 \%$ & \\
\hline \multirow[t]{2}{*}{ Multifocal tumour } & No & 292 & $91.8 \%$ & 366 & $85.9 \%$ & \multirow[t]{2}{*}{0.013} \\
\hline & Yes & 26 & $8.2 \%$ & 60 & $14.1 \%$ & \\
\hline \multirow[t]{2}{*}{ EIC } & 0 & 287 & $90.3 \%$ & 397 & $93.2 \%$ & \multirow[t]{2}{*}{0.145} \\
\hline & 1 & 31 & $9.7 \%$ & 29 & $6.8 \%$ & \\
\hline \multirow[t]{3}{*}{ Tumour grade } & 1 & 145 & $45.6 \%$ & 203 & $47.7 \%$ & \multirow[t]{3}{*}{0.444} \\
\hline & 2 & 130 & $40.9 \%$ & 156 & $36.6 \%$ & \\
\hline & 3 & 43 & $13.5 \%$ & 67 & $15.7 \%$ & \\
\hline \multirow[t]{2}{*}{ ER } & Negative & 22 & $7.0 \%$ & 26 & $6.1 \%$ & \multirow[t]{2}{*}{0.644} \\
\hline & Positive & 294 & $93.0 \%$ & 399 & $93.9 \%$ & \\
\hline \multirow[t]{2}{*}{ PR } & Negative & 77 & $24.4 \%$ & 103 & $24.2 \%$ & \multirow[t]{2}{*}{0.967} \\
\hline & Positive & 239 & $75.6 \%$ & 322 & $75.8 \%$ & \\
\hline \multirow[t]{3}{*}{ Ki-67 } & $0-15 \%$ & 216 & $69.0 \%$ & 308 & $72.5 \%$ & 0.031 \\
\hline & $16-30 \%$ & 58 & $18.5 \%$ & 88 & $20.7 \%$ & \\
\hline & $>30 \%$ & 39 & $12.5 \%$ & 29 & $6.8 \%$ & \\
\hline HER-2 & Negative & 296 & $93.7 \%$ & 391 & $92.0 \%$ & 0.387 \\
\hline & Positive & 20 & $6.3 \%$ & 34 & $8.0 \%$ & \\
\hline Lymph node status & pNO & 259 & $81.4 \%$ & 330 & $77.5 \%$ & 0.243 \\
\hline & pN1mic & 24 & $7.5 \%$ & 31 & $7.3 \%$ & \\
\hline & pN1mac & 35 & $11.0 \%$ & 65 & $15.3 \%$ & \\
\hline Radiotherapy & No & 10 & $3.1 \%$ & 20 & $4.7 \%$ & 0.288 \\
\hline & Yes & 308 & $96.9 \%$ & 406 & $95.3 \%$ & \\
\hline Adjuvant treatment & No & 101 & $31.8 \%$ & 95 & $22.3 \%$ & 0.020 \\
\hline & Endocrine treatment & 141 & $44.3 \%$ & 226 & $53.1 \%$ & \\
\hline & Chemotherapy & 8 & $2.5 \%$ & 16 & $3.8 \%$ & \\
\hline & Both & 68 & $21.4 \%$ & 89 & $20.9 \%$ & \\
\hline & & Med & & Med & & \\
\hline Age (years) & & $62(3$ & & $64(3$ & & 0.033 \\
\hline Tumour size $(\mathrm{mm})$ & & $10(1$ & & $11(1$ & & 0.219 \\
\hline Smallest lateral surgical margin (mm) & & $10(C$ & & $10(C$ & & 0.011 \\
\hline Specimen weight $(\mathrm{g})$ & & $55(1$ & & $60(\varepsilon$ & & 0.142 \\
\hline
\end{tabular}

Abbreviations: ROLL, radioguided occult lesion localization; RSL, radioactive seed localization; BCS, breast conserving surgery; EIC, extensive intraductal component. ER, estrogen receptor; PR, progesterone receptor; Ki-67, proliferation marker; HER-2, human epidermal growth factor receptor.

Nineteen patients died during the follow-up, 11 (4.3\%) in the ROLL group and eight $(2.5 \%)$ in the RSL group (Fisher's test, $\mathrm{p}=0.250)$. Only one $(0.4 \%)$ patient in ROLL group and two $(0.6 \%)$ in the RSL group died from breast cancer (Fisher's test, $\mathrm{p}=1.000$ ).

\subsection{Patients with pure DCIS}

The results for patients with DCIS are summarized in Table 5. ROLL was performed only in 13 cases and RSL in 30 . There was no statistically significant differences between the groups regarding size, multifocality or grade of DCIS, or regarding reoperation rates or adjuvant treatment.

\section{Discussion}

\subsection{Main message}

This study showed that ROLL and RSL provided similar outcomes regarding insufficient margin status, reoperation rates and LRFS in patients with impalpable invasive breast cancer treated with BCS. Instead of localization method, the risk factors for reoperations were multifocality of the tumour, larger tumour size, EIC and smaller specimen weight. This is consistent with previous studies $[11,13]$. There were more multifocal tumours in the RSL group. ROLL was not used in our unit if the tumour was multifocal in preoperative imaging; previously patients with multifocal lesions underwent WGL.

\subsection{Reoperations}

In our series, the reoperation rate due to insufficient margins was low (5.6\%) compared to previous studies of ROLL or RSL. In the systematic review and meta-analysis by Lovrics et al. [4] the reoperation rate after ROLL excision was $6.2-33.3 \%$ and after RSL 7.8-9.6\%. In more recent studies the reoperation rate after both ROLL and RSL has shown to be 7-13\% [5,9-11,18-20]. Velazco et al. though, showed lower re-excision rate in their study of RSL (2.3-4.1\%) [21]. Insufficient surgical margins and indications for reoperation are variable in the studies, making the comparison of studies difficult.

There are only few previous studies comparing ROLL and RSL. Van der Noordaa et al. compared these two localization techniques in their study [9] and did not find significant difference in reoperation rates (ROLL 10\% vs. RSL 9\%). Neither did Donker et al. [10], who 
Table 2

Patient and tumour characteristics for reoperations due to inadequate margins.

\begin{tabular}{|c|c|c|c|c|c|c|}
\hline & & \multicolumn{5}{|c|}{ Reoperation due to inadequate margins } \\
\hline & & \multicolumn{2}{|c|}{ Yes } & \multicolumn{2}{|l|}{ No } & \multirow[t]{3}{*}{ p-value } \\
\hline & & \multicolumn{2}{|c|}{$\mathrm{N}=42(5.6 \%)$} & \multicolumn{2}{|c|}{$\mathrm{N}=702(94.4 \%)$} & \\
\hline & & $\mathrm{N}$ & $\%$ & $\mathrm{~N}$ & $\%$ & \\
\hline \multirow[t]{2}{*}{ Localization method } & ROLL & 13 & $31.0 \%$ & 305 & $43.4 \%$ & 0.112 \\
\hline & RSL & 29 & $69.0 \%$ & 397 & $56.6 \%$ & \\
\hline \multirow[t]{2}{*}{ Reoperation } & Re-excision & 11 & $26.2 \%$ & 0 & $0.0 \%$ & \\
\hline & Mastectomy & 31 & $73.8 \%$ & 0 & $0.0 \%$ & \\
\hline \multirow[t]{3}{*}{ Histology } & Invasive ductal carcinoma & 28 & $66.7 \%$ & 493 & $70.2 \%$ & 0.863 \\
\hline & Invasive lobular carcinoma & 6 & $14.3 \%$ & 96 & $13.7 \%$ & \\
\hline & Other invasive & 8 & $19.0 \%$ & 113 & $16.1 \%$ & \\
\hline \multirow[t]{2}{*}{ Multifocal tumour } & $\mathrm{N}$ & 24 & $57.1 \%$ & 634 & $90.3 \%$ & $<0.001$ \\
\hline & Ye & 18 & $42.9 \%$ & 68 & $9.7 \%$ & \\
\hline \multirow[t]{2}{*}{ EIC } & 0 & 30 & $71.4 \%$ & 654 & $93.2 \%$ & $<0.001$ \\
\hline & 1 & 12 & $28.6 \%$ & 48 & $6.8 \%$ & \\
\hline \multirow[t]{3}{*}{ Tumour grade } & 1 & 13 & $31.0 \%$ & 335 & $47.7 \%$ & 0.107 \\
\hline & 2 & 21 & $50.0 \%$ & 265 & $37.7 \%$ & \\
\hline & 3 & 8 & $19.0 \%$ & 102 & $14.5 \%$ & \\
\hline \multirow[t]{2}{*}{ ER } & Negative & 5 & $11.9 \%$ & 43 & $6.2 \%$ & 0.141 \\
\hline & Positive & 37 & $88.1 \%$ & 656 & $93.8 \%$ & \\
\hline \multirow[t]{2}{*}{ PR } & Negative & 13 & $31.0 \%$ & 167 & $23.9 \%$ & 0.300 \\
\hline & Positive & 29 & $69.0 \%$ & 532 & $76.1 \%$ & \\
\hline \multirow[t]{3}{*}{ Ki-67 } & $0-15 \%$ & 27 & $65.9 \%$ & 497 & $71.3 \%$ & 0.491 \\
\hline & $16-30$ & 11 & $26.8 \%$ & 135 & $19.4 \%$ & \\
\hline & $>30 \%$ & 3 & $7.3 \%$ & 65 & $9.3 \%$ & \\
\hline \multirow[t]{2}{*}{ HER-2 } & Negativ & 36 & $85.7 \%$ & 651 & $93.1 \%$ & 0.072 \\
\hline & Positiv & 6 & $14.3 \%$ & 48 & $6.9 \%$ & \\
\hline \multirow[t]{4}{*}{ Lymph node status } & pNO & 28 & $66.7 \%$ & 561 & $79.9 \%$ & 0.095 \\
\hline & pN1mic & 4 & $9.5 \%$ & 51 & $7.3 \%$ & \\
\hline & pN1mac & 10 & $23.8 \%$ & 90 & $12.8 \%$ & \\
\hline & & \multicolumn{2}{|c|}{ Median (range) } & \multicolumn{2}{|c|}{ Median (range) } & \\
\hline \multicolumn{2}{|l|}{ Age (years) } & \multicolumn{2}{|c|}{$64(36-85)$} & \multicolumn{2}{|c|}{$62(38-91)$} & 0.243 \\
\hline \multicolumn{2}{|l|}{ Tumour size (mm) } & \multicolumn{2}{|c|}{$13(1-40)$} & \multicolumn{2}{|c|}{$10(1-55)$} & 0.112 \\
\hline \multicolumn{2}{|l|}{ Specimen weight (g) } & \multicolumn{2}{|c|}{$50(12-298)$} & \multicolumn{2}{|c|}{$58(8-1893)$} & 0.055 \\
\hline
\end{tabular}

Abbreviations: ROLL, radioguided occult lesion localization; RSL, radioactive seed localization; EIC, extensive intraductal component.

ER, estrogen receptor; PR, progesterone receptor; Ki-67, proliferation marker; HER-2, human epidermal growth factor receptor.

Table 3

Risk factors for reoperation using binary logistic regression analysis.

\begin{tabular}{|c|c|c|c|c|c|}
\hline & & \multirow[t]{2}{*}{ OR } & \multicolumn{2}{|c|}{ 95\% C.I. for OR } & \multirow[t]{2}{*}{ p-value } \\
\hline & & & Lower & Upper & \\
\hline \multirow[t]{3}{*}{ Lymph node status } & pNO & 1 & & & 0.900 \\
\hline & pN1mic & 1.185 & 0.333 & 4.223 & 0.793 \\
\hline & pN1mac & 1.226 & 0.476 & 3.155 & 0.673 \\
\hline \multirow[t]{2}{*}{ HER-2 } & Negative & 1 & & & \\
\hline & Positive & 1.506 & 0.445 & 5.095 & 0.510 \\
\hline \multirow[t]{2}{*}{ ER } & Negative & 1 & & & \\
\hline & Positive & 0.498 & 0.128 & 1.945 & 0.316 \\
\hline \multirow[t]{3}{*}{ Tumour grade } & 1 & 1 & & & 0.294 \\
\hline & 2 & 1.880 & 0.849 & 4.163 & 0.119 \\
\hline & 3 & 1.382 & 0.465 & 4.113 & 0.560 \\
\hline \multirow[t]{2}{*}{ Localization method } & ROLL & 1 & & & \\
\hline & RSL & 1.614 & 0.771 & 3.381 & 0.204 \\
\hline \multirow[t]{2}{*}{ Multifocal tumour } & No & 1 & & & \\
\hline & Yes & 8.968 & 4.263 & 18.866 & $<0.001$ \\
\hline \multirow[t]{2}{*}{ EIC } & No & 1 & & & \\
\hline & Yes & 6.214 & 2.626 & 14.702 & $<0.001$ \\
\hline Tumour size & & 1.077 & 1.017 & 1.140 & 0.011 \\
\hline Specimen weight & & 0.988 & 0.979 & 0.998 & 0.014 \\
\hline
\end{tabular}

Abbreviations: OR, odds ratio; C.I. confidence interval; HER-2, human epidermal growth factor receptor; ER, estrogen receptor.

ROLL, radioguided occult lesion localization; RSL, radioactive seed localization; EIC, extensive intraductal component.

compared ROLL and RSL after neoadjuvant treatment (ROLL 7\% vs. RSL 8\%). Theunissen et al. [11] compared all WGL, ROLL and RSL and they found that RSL results in a higher negative surgical margin rate and lower reoperation rate.

\subsection{Specimen weight}

In this study we did not find any difference in specimen weight between the ROLL and RSL ( $\mathrm{p}=0.143$ ), similarly to other previously published studies [9-11]. Our study material includes all patients 
Table 4

Breast cancer events observed during follow-up.

\begin{tabular}{|c|c|c|c|}
\hline & $\operatorname{ROLL}(\mathrm{N}=258)$ & $\operatorname{RSL}(N=321)$ & p-value (Fisher) \\
\hline Follow-up time, median (range) & $81(8-94)$ months & $64(3-73)$ months & \\
\hline Event & $\mathrm{N}(\%)$ & $\mathrm{N}(\%)$ & \\
\hline Ipsilateral breast recurrence & $7(2.7 \%)$ & $3(0.9 \%)$ & 0.119 \\
\hline Contralateral breast recurrence & $3(1.2 \%)$ & $2(0.6 \%)$ & 0.660 \\
\hline Regional lymph node recurrence & $3(1.2 \%)$ & $1(0.3 \%)$ & 0.329 \\
\hline Ipsilateral axilla & $1(0.4 \%)$ & $1(0.3 \%)$ & \\
\hline Contralateral axilla & $1(0.4 \%)$ & 0 & \\
\hline Supraclavicular node ${ }^{c}$ & $1(0.4 \%)$ & 0 & \\
\hline Distant metastasis & $3(1.2 \%)$ & $3(0.9 \%)$ & 1.000 \\
\hline Death from breast cancer & $1(0.4 \%)$ & $2(0.6 \%)$ & 1.000 \\
\hline Death from any cause & $11(4.3 \%)$ & $8(2.5 \%)$ & 0.250 \\
\hline
\end{tabular}

Abbreviations: ROLL, radioguided occult lesion localization; RSL, radioactive seed localization.

a The patients in both groups had concomitant LR.

b The patient had concomitant LR and distant metastasis.

c The patient had concomitant distant metastasis.

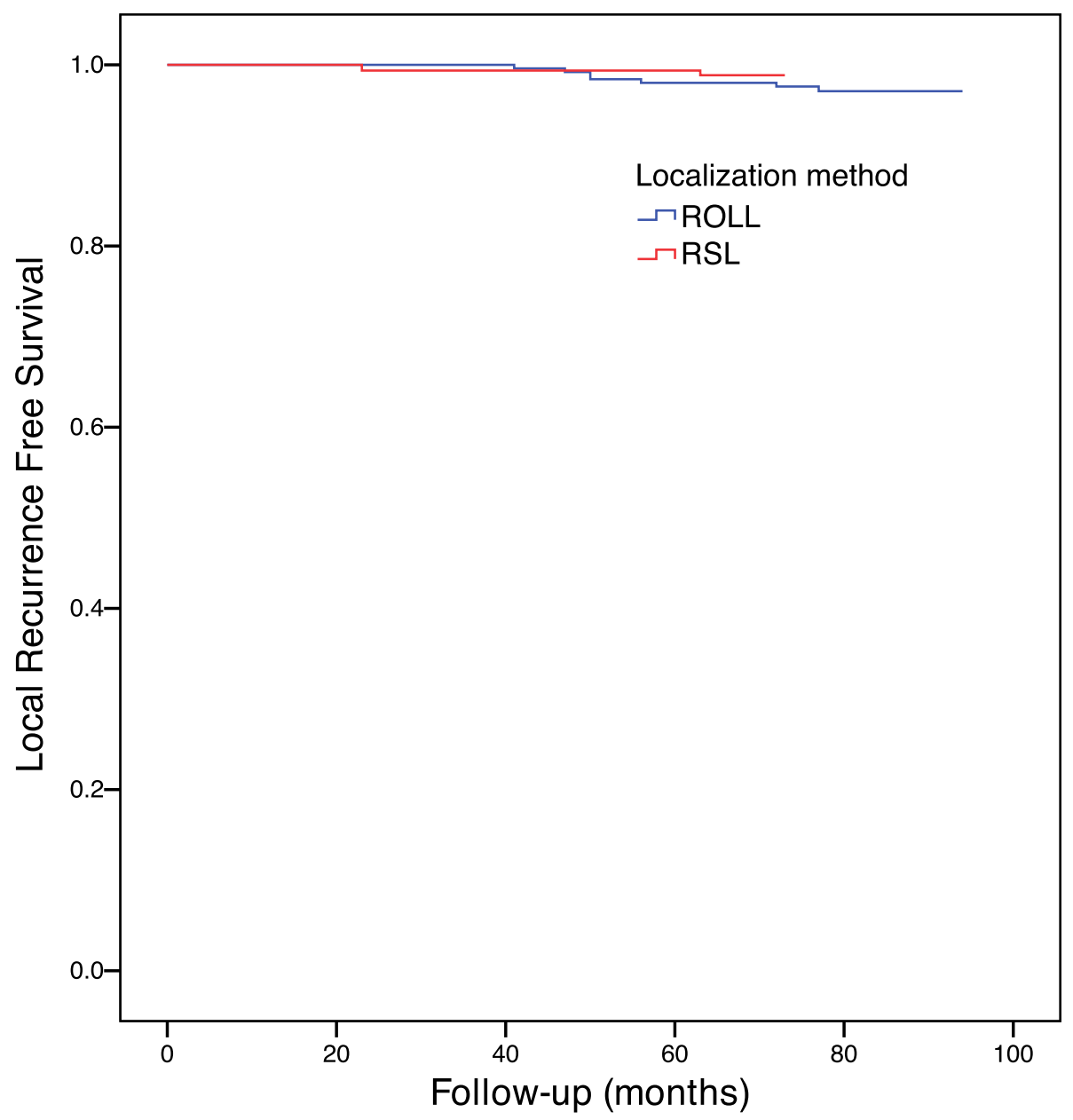

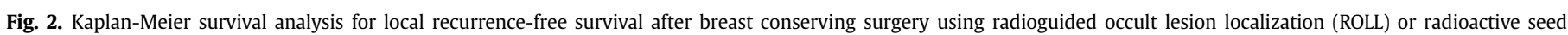
localization (RSL).

who underwent BCS, with either conventional or oncoplastic resection, therefore there is a wide range in specimen weights. We did not evaluate specimen volumes, since determining tumourresection volume ratio in large oncoplastic resection specimens is not relevant.

In our study, the RSL group included more often multifocal disease and this possibly increased the specimen weights of the group. However, larger specimen weights may not result in poorer aesthetic result in the era of oncoplastic surgery, which is used more and more in our unit [22].

\subsection{Local recurrences}

In our series, there was no difference in the estimated five-year 
Table 5

ROLL and RSL for DCIS cases.

\begin{tabular}{|c|c|c|c|c|c|c|}
\hline & & \multicolumn{2}{|c|}{ ROLL N = $13(30.2 \%)$} & \multicolumn{2}{|c|}{$\begin{array}{l}\text { RSL N = } 30 \\
(69.8 \%)\end{array}$} & \multirow[t]{2}{*}{ p-value } \\
\hline & & $\mathrm{N}$ & $\%$ & $\mathrm{~N}$ & $\%$ & \\
\hline \multirow[t]{2}{*}{ Surgery } & Conventional BCS & 8 & $61.5 \%$ & 23 & $76.7 \%$ & \multirow[t]{2}{*}{0.310} \\
\hline & Oncoplastic BCS & 5 & $38.5 \%$ & 7 & $23.3 \%$ & \\
\hline \multirow[t]{2}{*}{ Reoperation due to insufficient margins } & No & 12 & $92.3 \%$ & 25 & $83.3 \%$ & \multirow[t]{2}{*}{0.435} \\
\hline & Yes & 1 & $7.7 \%$ & 5 & $16.7 \%$ & \\
\hline \multirow[t]{2}{*}{ DCIS multifocality } & No & 12 & $92.3 \%$ & 25 & $83.3 \%$ & \multirow[t]{2}{*}{0.435} \\
\hline & Yes & 1 & $7.7 \%$ & 5 & $16.7 \%$ & \\
\hline \multirow[t]{4}{*}{ DCIS grade } & 1 & 1 & $7.7 \%$ & 2 & $6.7 \%$ & \multirow[t]{4}{*}{0.405} \\
\hline & 2 & 3 & $23.1 \%$ & 14 & $46.7 \%$ & \\
\hline & 3 & 9 & $69.2 \%$ & 13 & $43.3 \%$ & \\
\hline & NA & 0 & $0.0 \%$ & 1 & $3.3 \%$ & \\
\hline \multirow[t]{2}{*}{ Radiotherapy } & No & 2 & $15.4 \%$ & 1 & $3.3 \%$ & \multirow[t]{2}{*}{0.154} \\
\hline & Yes & 11 & $84.6 \%$ & 29 & $96.7 \%$ & \\
\hline \multirow[t]{2}{*}{ Adjuvant treatment } & Endocrine treatment & 0 & $0.0 \%$ & 1 & $3.3 \%$ & \multirow[t]{2}{*}{0.497} \\
\hline & Endocrine treatment and chemotherapy & 0 & $0.0 \%$ & 2 & $6.7 \%$ & \\
\hline \multirow[t]{2}{*}{ Ipsilateral breast recurrence } & & 0 & $0.0 \%$ & 1 & $3.3 \%$ & \multirow[t]{4}{*}{0.505} \\
\hline & & Median (range) & Median (range) & & & \\
\hline Age (years) & $60(49-83)$ & $58(43-88)$ & 0.276 & & & \\
\hline DCIS histological size (mm) & $10(4-30)$ & $12(3-40)$ & 0.936 & & & \\
\hline
\end{tabular}

Abbreviations: DCIS, ductal carcinoma in situ; ROLL, radioguided occult lesion localization.

RSL, radioactive seed localization; BCS, breast conserving surgery; NA, Not available.

a Chemotherapy due to contralateral invasive breast cancer.

LRSF for ROLL and RSL groups (Fig. 2). There are only few previous studies reporting LR rates after BCS using ROLL or RSL. Theunissen et al. [11] reported a LR rate of $6.6 \%$ in the ROLL group (median follow-up 51 months) and no recurrences in the RSL group (median follow-up 33 months). A recent study by Aljohani et al. [19] reported a LR of only $0.3 \%$, but the median follow-up time was just 37 months in the RSL group.

Contralateral breast cancer recurrences, regional lymph node recurrences and breast cancer deaths were rare in our study.

\subsection{Strengths and limitations of the study}

In this study, we reviewed a large number of patients. This is a single-center study, the diagnostic and treatment protocols, including surgical practice, are standardized at our institution.

A limitation of this study is that data was collected retrospectively. Consequently, the RSL group patients had more often multifocal disease and received more often endocrine treatment, perhaps partly due to the multifocality, as there was no difference in tumour sizes. In addition, we excluded DCIS from the main analysis due to the small number of cases, especially in the ROLL group. DCIS is a known risk factor for positive margins and this may bias our findings. Among DCIS patients, we did not find statistically significant differences between ROLL and RSL, neither in the DCIS characteristics nor in the reoperation rate, possibly due the very small number of patients.

Furthermore, the guidelines for adequate surgical margins changed at the beginning of the study period in 2010. The new recommendation 'no ink on tumour' was introduced gradually, hence the indication for reoperation is not standard throughout the study period and was favoring RSL.

\subsection{Other aspects of ROLL and RSL}

Even though we did not find any difference in surgical outcome or oncological safety between ROLL and RSL, there are some clear advantages with RSL. The seeds are visible in mammography and their correct positioning is easy thus to confirm. RSL might also provide more accurate localization, since there is a risk of dispersion of Tc-99 m during the injection for ROLL. With RSL, it is possible to mark multiple lesions or a large microcalcification area with $2-3$ seeds, which is a clear advantage compared to ROLL.

RSL provides flexible scheduling and logistics, since the seed can be placed weeks or even several months before surgery, for example in patients undergoing neoadjuvant treatment. It is quite common that when inserting the seed, the radiologist detects another suspicious lesion not identified in earlier imaging and biopsies or even re-planning of surgery may be needed [5]. Hence, we schedule the RSL well before operation.

On the other hand, due to the long half-life of I-125 seed, careful handling and disposal protocols are needed [9]. An advantage of ROLL is that it can be performed simultaneously with SNLB using a single injection of radiolabeled colloid $[23,24]$.

\subsection{Future aspects}

Because WGL, ROLL and RSL have all some disadvantages, several new localization methods have been developed [24-26]. Non-ionizing markers using magnetic technology and radiofrequency energy are already in clinical use as well as intraoperative US. In addition, many other techniques are under investigation. Long-term evidence is needed to evaluate the feasibility of these new localization methods.

\section{Conclusion}

ROLL and RSL provided similar surgical outcomes in terms of margin status, reoperation rates and LRFS in patients with impalpable invasive breast cancer treated with BCS.

\section{Conflicts of interest}

None.

\section{Ethics}

This retrospective study did not require an ethics committee permission, but was approved by the institutional research board of Helsinki University Hospital. 


\section{Funding}

The corresponding author was supported by research funds of the Helsinki University Hospital.

\section{Appendix A. Supplementary data}

Supplementary data to this article can be found online at https://doi.org/10.1016/j.breast.2019.07.004.

\section{References}

[1] Behm EC, Beckmann KR, Dahlstrom JE, Zhang Y, Cho C, Stuart-Harris R, et al. Surgical margins and risk of locoregional recurrence in invasive breast cancer: an analysis of 10-year data from the Breast Cancer Treatment Quality Assurance Project. Breast 2013 Oct;22(5):839-44.

[2] Tafra L, Fine R, Whitworth P, Berry M, Woods J, Ekbom G, et al. Prospective randomized study comparing cryo-assisted and needle-wire localization of ultrasound-visible breast tumors. Am J Surg 2006;192:462-70.

[3] Mariscal Martínez A, Solà M, de Tudela AP, Julián JF, Fraile M, Vizcaya S, et al. Radioguided localization of nonpalpable breast cancer lesions: randomized comparison with wire localization in patients undergoing conservative surgery and sentinel node biopsy. AJR Am J Roentgenol 2009;193:1001-9.

[4] Lovrics PJ, Cornacchi SD, Vora R, Goldsmith CH, Kahnamoui K. Systematic review of radioguided surgery for non-palpable breast cancer. Eur I Surg Oncol 2011;37:388-97.

[5] Milligan R, Pieri A, Critchley A, Peace R, Lennard T, O'Donoghue JM, et al Radioactive seed localization compared with wire-guided localization of nonpalpable breast carcinoma in breast conservation surgery- the first experience in the United Kingdom. Br J Radiol 2018 Jan;91(1081):20170268.

[6] Chan BK, Wiseberg-Firtell JA, Jois RH, Jensen K, Audisio RA. Localization techniques for guided surgical excision of non-palpable breast lesions. Cochrane Database Syst Rev 2015 Dec 31;(12):CD009206.

[7] Sajid MS, Parampalli U, Haider Z, Bonomi R. Comparison of radioguided occult lesion localization (ROLL) and wire localization for non-palpable breast cancers: a meta-analysis. J Surg Oncol 2012 Jun 15;105(8):852-8.

[8] Ahmed M, Douek M. Radioactive seed localisation (RSL) in the treatment of non-palpable breast cancers: systematic review and meta-analysis. Breast 2013 Aug;22(4):383-8.

[9] Van der Noordaa ME, Pengel KE, Groen E, van Werkhoven E, Rutgers EJ Loo CE, et al. The use of radioactive iodine-125 seed localization in patients with non-palpable breast cancer: a comparison with the radioguided occult lesion localization with 99m technetium. Eur J Surg Oncol 2015 Apr;41(4): 553-8.

[10] Donker M, Drukker CA, Valdés Olmos RA, Rutgers EJ, Loo CE, Sonke GS, et al. Guiding breast-conserving surgery in patients after neoadjuvant systemic therapy for breast cancer: a comparison of radioactive seed localization with the ROLL technique. Ann Surg Oncol 2013 Aug;20(8):2569-75.

[11] Theunissen CI, Rust EA, Edens MA, Bandel C, Van't Ooster-van den Berg JG, Jager PL, et al. Radioactive seed localization is the preferred technique in nonpalpable breast cancer compared with wire-guided localization and radioguided occult lesion localization. Nucl Med Commun 2017 May;38(5): 396-401.

[12] Clough KB, Kaufman GJ, Nos C, Buccimazza I, Sarfati IM. Improving breast cancer surgery: a classification and quadrant per quadrant atlas for oncoplastic surgery. Ann Surg Oncol 2010 May;17(5):1375-91.

[13] Niinikoski L, Leidenius MHK, Vaara P, Voynov A, Heikkilä P, Mattson J, et al Resection margins and local recurrences in breast cancer: comparison between conventional and oncoplastic breast conserving surgery. Eur J Surg Oncol 2019 Feb 11;(19). https://doi.org/10.1016/j.ejso.2019.02.010. pii: S0748-7983, 30279-3.

[14] Kaufmann M, Morrow M, von Minckwitz G, Harris JR, Biedenkopf Expert Panel Members. Locoregional treatment of primary breast cancer: consensus recommendations from an International Expert Panel. Cancer 2010 Mar 1;116(5):1184-91.

[15] Leidenius MH, Vironen JH, Heikkilä PS, Joensuu H. Influence of isolated tumor cells in sentinel nodes on outcome in small, node-negative (pT1NOM0) breast cancer. Ann Surg Oncol 2010 Jan;17(1):254-62.

[16] Finnish Breast Cancer Group. Rintasyövän valtakunnallinen diagnostiikka- ja hoitosuositus. 2018. https://rintasyoparyhma.yhdistysavain.fi/@Bin/181912/ Rintasy\%C3\%B6v\%C3\%A4n\%20valtakunnallinen\%20diagnostiikka-\%20ja\% 20hoitosuositus\%206.2018.pdf (updated 6/2018).

[17] Liikanen J, Leidenius M, Joensuu H, Vironen J, Heikkilä P, Meretoja T. Breast cancer prognosis and isolated tumor cell findings in axillary lymph nodes after core needle biopsy and fine needle aspiration cytology: biopsy method and breast cancer outcome. Eur J Surg Oncol 2016 Jan;42(1):64-70.

[18] Zhang Y, Seely J, Cordeiro E, Hefler J, Thavorn K, Mahajan M, et al. Radioactive seed localization versus wire-guided localization for nonpalpable breast cancer: a cost and operating room efficiency analysis. Ann Surg Oncol 2017 Nov;24(12):3567-73.

[19] Aljohani B, Jumaa K, Kornecki A, Brackstone M. Clinical utility of radioactive seed localization in nonpalpable breast cancer: a retrospective single institutional cohort study. Int J Surg 2018 Dec;60:149-52.

[20] Pieri A, Milligan R, Critchley A, O'Donoghue JM, Sibal N, Peace R, et al. The introduction of radioactive seed localisation improves the oncological outcome of image guided breast conservation surgery. Breast 2017 Dec;36: 49-53.

[21] Velazco CS, Wasif N, Pockaj BA, Gray RJ. Radioactive seed localization for breast conservation surgery: low positive margin rate with no learning curve. Am J Surg 2017 Dec;214(6):1091-3.

[22] Ojala K, Meretoja TJ, Leidenius MH. Aesthetic and functional outcome after breast conserving surgery - comparison between conventional and oncoplastic resection. Eur J Surg Oncol 2017 Apr;43(4):658-64.

[23] Rönkä R, Krogerus L, Leppänen E, von Smitten K, Leidenius M. Radio-guided occult lesion localization in patients undergoing breast-conserving surgery and sentinel node biopsy. Am J Surg 2004 Apr;187(4):491-6.

[24] Ahmed M, Rubio IT, Klaase JM, Douek M. Surgical treatment of nonpalpable primary invasive and in situ breast cancer. Nat Rev Clin Oncol 2015 Nov:12(11):645-63.

[25] Mayo 3rd RC, Kalambo MJ, Parikh JR. Preoperative localization of breast lesions: current techniques. Clin Imaging 2019 Jan 16;56:1-8.

[26] Gray RJ, Pockaj BA, Garvey E, Blair S. Intraoperative margin management in breast-conserving surgery: a systematic review of the literature. Ann Surg Oncol 2018 Jan;25(1):18-27. 